\title{
Mathematical modeling and optimization of semi-regenerative catalytic reforming of naphtha
}

\author{
Emilia Ivanchina ${ }^{1}$, Ekaterina Chernyakova $^{1, *}$ (D), Inna Pchelintseva ${ }^{2}$ (D), and Dmitry Poluboyartsev ${ }^{3}$ \\ ${ }^{1}$ Division for Chemical Engineering, National Research Tomsk Polytechnic University, 30, Lenin Avenue, 634050 Tomsk, Russia \\ ${ }^{2}$ Well Testing Center "GasInformPlast", 8, Razvitiya Avenue, 634055 Tomsk, Russia \\ ${ }^{3}$ Joint Stock Company "Tomsk Oil and Gas Research and Design Institute", 72, Mira Avenue, 634027 Tomsk, Russia
}

Received: 15 April 2021 / Accepted: 20 July 2021

\begin{abstract}
Catalytic naphtha reforming is extensively applied in petroleum refineries and petrochemical industries to convert low-octane naphtha into high-octane gasoline. Besides, this process is an important source of hydrogen and aromatics obtained as side products. The bifunctional Pt-catalysts for reforming are deactivated by coke formation during an industrial operation. This results to a reduction in the yield and octane number. In this paper modeling and optimization of a semi-regenerative catalytic reforming of naphtha is carried out considering catalyst deactivation and a complex multicomponent composition of a hydrocarbon mixture. The mathematical model of semi-regenerative catalytic reforming considering coke formation process was proposed. The operating parameters (yield, octane number, activity) for different catalysts were predicted and optimized. It was found that a decrease in the pressure range from 1.5 to $1.2 \mathrm{MPa}$ at the temperature $478-481{ }^{\circ} \mathrm{C}$ and feedstock space velocity equal to $1.4-1 \mathrm{~h}$ induces an increase in the yield for $1-2$ wt.\% due to an increase in the aromatization reactions rate and a decrease in the hydrocracking reactions rate depending on the feedstock composition and catalyst type. It is shown that the decrease in pressure is limited by the requirements for the catalyst stability due to the increase in the coke formation rate. The criterion of optimality is the yield, expressed in octanes per tons.
\end{abstract}

\section{Introduction}

Catalytic reforming of naphtha is one of the most significant petrochemical processes in the world based on obtaining a high-octane component for motor fuel. Hydrogen is obtained as a valuable side product that is demanded in most refineries for hydrogen-consuming processes such as hydrotreating, hydrocracking, etc. Besides, the produced reformate contains aromatics namely Benzene, Toluene, Xylene (BTX) that are very valuable and important petrochemical material [1-4].

There are several types of reactions, which occur during catalytic reforming process. They include the reactions of dehydrogenation, isomerization, cyclization, aromatization, hydrocracking, hydrogenolysis, and coke formation. Some of these reactions increase octane number (isomerization, cyclization, aromatization), while the others can cause catalyst deactivation process (coke formation). The catalytic reforming reactions take place in the reactors on the layer of a catalyst consisting of $\mathrm{Al}_{2} \mathrm{O}_{3}$ support of $\gamma$-modification and metals (Pt, Re, Ir, Ge, Sn, Cd) and additionally

\footnotetext{
* Corresponding author: sharova@tpu.ru
}

promoted by chlorine. Generally, the industrial reforming process is carried out in three or four adiabatically operated reactors at temperatures from 470 to $510{ }^{\circ} \mathrm{C}$ and total pressures between 5 and $20 \mathrm{~atm}$. A preliminary hydrodesulfurized naphtha cut is used as feedstock.

There are three main groups of catalyst regeneration procedures according to which industrial naphtha reforming units are classified into Semi-Regenerative catalytic Reformers (SRR), Continuous catalyst Regeneration Reformers (CCR) and cyclic catalytic reformers. SRR is the most commonly used scheme - about $60 \%$ of the total capacity. In this unit, the research octane number can be achieved in the range of $85-100$. This process is characterized by its continuous operation over a long period; the shutdown of SRR unit occurs once each 6-24 months due to the decreased catalyst activity.

Catalytic naphtha reforming has already been vastly improved by many researchers who investigated different aspects of this industrial process, namely development of more effective catalysts, design of an efficient reactor configuration and a mode of operation or the appropriate kinetic and deactivation models [5-11]. Still, in spite of a plethora of existing papers, there is a need for more research in 
revealing and elucidating kinetic and deactivation mechanisms as well as suggesting more efficient reactor setups and modes of operation.

Methods of catalytic reforming process research are divided into instrumental and kinetic. The first group of methods includes the study of physico-chemical catalyst characteristics, namely composition, structure and texture (porosity, specific surface, etc.). The second group explains a formalized mechanism of process reactions on the catalyst surface and allows obtaining the initial data for optimal management by determining the kinetic parameters of the reactions. There is one more method for study of complex hydrocarbon processes and it is successfully applied for catalytic naphtha reforming - mathematical modeling. A mathematical model of a process is based on its kinetic model and process parameters.

All reforming catalysts undergo deactivation process. A lot of scientific works are devoted to study this process $[12,13]$. For heterogeneous catalysts of reforming, isomerization and dehydrogenation processes, deactivation is the result of deposition of coxogenic compounds on their surface. In these processes, deactivation is accompanied by selfregeneration of coke under the influence of the components of the mixture (hydrogen, water, etc.). The level of stationary (optimal) activity is established when the rates of deactivation and self-regeneration are equal to each other [14].

Our previous studies of catalyst deactivation were devoted to its reversible type. By maintaining the equilibrium reaction of coke formation and hydrogenation of the intermediate products of compaction, the level of optimal activity of a catalyst is achieved, at which its selfregeneration occurs [8]. The operation under the conditions of the equal rates of coke formation and hydrogenation reactions, which are controlled by temperature under industrial conditions, consumption of feedstock and recycle hydrogen-containing gas, can significantly extend the inter-regeneration period of the reforming catalysts [15]. Based on the thermodynamic equilibrium conditions of the oxidation reaction of the coke compounds formed on the surface of platinum-containing dehydrogenation catalysts, the optimal modes of water supply to an industrial reactor were determined, which ensured an increase in the catalyst service life by $20 \%$ [16].

To develop this direction, the studies in the narrow pressure range (12-14 atm) should be considered. The main task in this case is the theoretical justification for the existence of the optimal conditions for the catalyst and the development of the recommendations for maintaining optimal pressure with the feedstock composition change in a given interval and technological conditions.

Modeling of catalytic naphtha reforming process is a very complex task because of a number of the features such as catalyst bimetallic nature, feedstock composition complexity, a large number of reactions with different rates and deactivation processes occurring during the catalyst operation. Therefore, a model should consider both the catalyst bimetallic nature and the complexity of the feedstock composition as in a real technological process [17-19].

The main task for mathematical modeling of the chemical processes is a sequential definition of thermodynamic and kinetic parameters of chemical transformations (chemical phenomena), the parameters of transport phenomena (physical phenomena), and the laws of their interaction. For this purpose, the experimental research data are used. The results of the process analysis and the study of its components make it possible to construct a mathematical model as an algebraic or differential system of equations. The model study is aimed at studying its properties, while computational methods are used. The obtained model properties should be further interpreted as the study object, which in this case is a chemical reactor.

\section{Materials and methods}

The methods of mathematical modeling have been intensively developed since the beginning of the 1960s [12-27]. The main idea of these methods is to study object properties with a mathematical model. A model and an object of investigation have different physical nature but the same properties. The mathematical model of a technological process is designed by a system of algebraic or differential system of equations adequately describing properties of an object.

Catalytic reforming of naphtha is a quite difficult technological process to study and to model because of:

- Complexity of naphtha and reformate hydrocarbon compositions containing more than 300 components.

- Many simultaneous reactions and differences in rates.

- Bifunctional mechanism of catalysts.

- Catalyst deactivation processes (poisoning, aging, erosion, breakage, coke deposition), contributing to a decrease in the catalyst activity and selectivity.

Construction of the mathematical model of catalytic naphtha reforming is based on the analysis of the process reactions mechanism. Each component of the hydrocarbon mixture of naphtha undergoes the reactions of dehydrogenation, isomerization, dehydrocyclization, hydrocracking, hydrogenolisis and hydrodealkilation. It would be too complicated to consider all the components and reactions in a kinetic model. Thus, all components of the mixture were classified in the homological groups called pseudo components and the formalized mechanism of the reactions was created taking into account the components reactivity (Fig. 1).

It is shown in Figure 1, that mechanism of coke can be represented as a scheme of reactions: hydrocarbons $\rightarrow$ resins $\rightarrow$ asphaltenes $\rightarrow$ coke, where resins and asphaltenes are Unsaturated Immediate Compacting Products (UICP) [28].

For the mathematical description of the hydrodynamic and heat model of catalytic reforming reactor, some assumptions are made:

- The formalized mechanism of hydrocarbons transformation (Fig. 1).

- The plug flow reactor model.

- The adiabatic operation. 


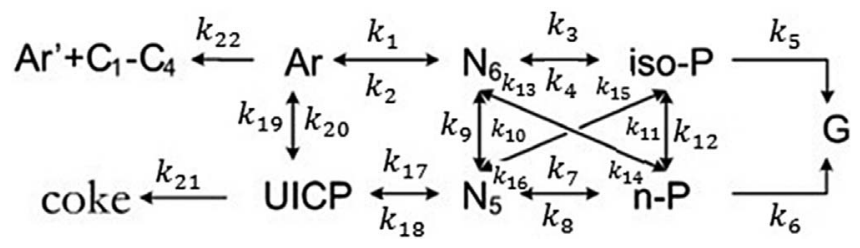

Fig. 1. Formalized reaction scheme of naphtha reforming: n-P, iso-P - normal and iso-alkanes; N-5, N-6 - cyclopentanes and cyclohexanes; Ar - aromatic hydrocarbons; UICP - Unsaturated Immediate Compacting Products; G - gas.

The rate law for the elementary steps is proportional to the concentration of the reacting substances in degrees showing a number of the interacting particles:

$$
r_{j}=k_{j} \cdot C_{i},
$$

where $r_{j}$ is a reaction rate; $k_{j}$ is a rate constant; $C_{i}$ is an initial component's concentration.

A kinetic model of catalytic reforming process can be written as an equation for the reactions of hydrogenolysis of naphthenes and hydrocracking of paraffins:

$$
\frac{\mathrm{d} C_{i}(x)}{\mathrm{d} t}=\sum_{j=1}^{n} k_{j}(x) \cdot C_{i}(x) \cdot C_{\mathrm{H}_{2}},
$$

where $j=1, \ldots, n$ is a number of chemical reaction; $C_{i}(x)$ and $k_{j}(x)$ are respectively distributions of hydrocarbons concentration and rate constants on a number of carbon atoms in a molecule $x ; t$ is a space time, $\mathrm{h}$.

According to Figure 1, the kinetic model of the catalytic reforming process is designed with the system of equations:

$$
\begin{aligned}
& r_{1}=k_{1} \cdot C_{\mathrm{Ar}} \cdot C_{\mathrm{H}_{2}} \\
& r_{2}=k_{2} \cdot C_{6} \\
& r_{3}=k_{3} \cdot C_{\mathrm{N}_{6}} \cdot C_{\mathrm{H}_{2}} \\
& r_{4}=k_{4} \cdot C_{\mathrm{iso}-\mathrm{P}} \\
& r_{5}=k_{5} \cdot C_{G} \cdot C_{\mathrm{H}_{2}} \\
& r_{6}=k_{6} \cdot C_{\mathrm{n}-\mathrm{P}} \cdot C_{\mathrm{H}_{2}} \\
& r_{7}=k_{7} \cdot C_{\mathrm{N}_{5}} \cdot C_{\mathrm{H}_{2}} \\
& r_{8}=k_{8} \cdot C_{\mathrm{n}-\mathrm{P}} \\
& r_{9}=k_{9} \cdot C_{\mathrm{N}_{5}} \\
& r_{10}=k_{10} \cdot C_{\mathrm{N}_{6}} \\
& r_{11}=k_{11} \cdot C_{\mathrm{n}-\mathrm{P}} \\
& r_{12}=k_{12} \cdot C_{\mathrm{iso}-\mathrm{P}} \\
& r_{13}=k_{13} \cdot C_{\mathrm{N}_{6}} \cdot C_{\mathrm{H}_{2}} \\
& r_{14}=k_{14} \cdot C_{\mathrm{n}-\mathrm{P}} \\
& r_{15}=k_{15} \cdot C_{\mathrm{N}_{5}} \cdot C_{\mathrm{H}_{2}}
\end{aligned}
$$

$$
\begin{aligned}
& r_{16}=k_{16} \cdot C_{\mathrm{iso}-\mathrm{P}} \\
& r_{17}=k_{17} \cdot C_{\mathrm{UICP}} \\
& r_{18}=k_{18} \cdot C_{\mathrm{N}_{5}} \\
& r_{19}=k_{19} \cdot C_{\mathrm{UICP}} \\
& r_{20}=k_{20} \cdot C_{\mathrm{Ar}} \\
& r_{22}=k_{22} \cdot C_{\mathrm{Ar}^{\prime}} .
\end{aligned}
$$

The equation of heat balance can be written as:

$$
\begin{aligned}
G \frac{\mathrm{d} T}{\mathrm{~d} V} & =\frac{1}{\rho \cdot C_{p}^{\text {mix }}} \sum_{j=1}^{m} Q_{j}, \\
Q_{j} & =\Delta H_{j} \cdot k_{j}(x) \cdot C_{j}(x),
\end{aligned}
$$

where $V$ is a catalyst volume in the reactors, $\mathrm{m}^{3} ; \rho$ is a density, $\mathrm{mol} / \mathrm{m}^{3} ; C_{p}^{\text {mix }}$ is a heat capacity of mixture, $\mathrm{kJ} / \mathrm{mol} \mathrm{K} ; Q_{j}$ is an amount of heat in a $j$ th chemical reaction; $\Delta \mathrm{H}$ is a $j$ th reaction heat, $\mathrm{kJ} / \mathrm{mol}$ :

$$
\begin{aligned}
& Q_{1}=\Delta \mathrm{H}_{1} \sum_{x}\left[k_{2} \cdot C_{\mathrm{N}_{6}}-k_{1} \cdot C_{\mathrm{Ar}} \cdot C_{\mathrm{H}_{2}}\right] \\
& Q_{2}=\Delta \mathrm{H}_{2} \sum_{x}\left[k_{4} \cdot C_{\mathrm{iso}-\mathrm{P}}-k_{3} \cdot C_{\mathrm{N}_{6}} \cdot C_{\mathrm{H}_{2}}\right] \\
& Q_{3}=-\Delta \mathrm{H}_{3} \sum_{x} k_{5} \cdot C_{\mathrm{iso}-\mathrm{P}} \cdot C_{\mathrm{H}_{2}} \\
& Q_{4}=-\Delta \mathrm{H}_{4} \sum_{x} k_{6} \cdot C_{\mathrm{n}-\mathrm{P}} \cdot C_{\mathrm{H}_{2}} \\
& Q_{5}=\Delta \mathrm{H}_{5} \sum_{x}\left[k_{11} \cdot C_{\mathrm{n}-\mathrm{P}}-k_{12} \cdot C_{\mathrm{iso}-\mathrm{P}}\right] \\
& Q_{6}=\Delta \mathrm{H}_{6} \sum_{x}\left[k_{8} \cdot C_{\mathrm{n}-\mathrm{P}}-k_{7} \cdot C_{\mathrm{N}_{5}} \cdot C_{\mathrm{H}_{2}}\right] \\
& Q_{7}=\Delta \mathrm{H}_{7} \sum_{x}\left[k_{10} \cdot C_{\mathrm{N}_{6}}-k_{9} \cdot C_{\mathrm{N}_{5}}\right] \\
& Q_{8}=\Delta \mathrm{H}_{8} \sum_{x}\left[k_{16} \cdot C_{\mathrm{iso}-\mathrm{P}}-k_{15} \cdot C_{\mathrm{N}_{5}} \cdot C_{\mathrm{H}_{2}}\right] \\
& Q_{9}=\Delta \mathrm{H}_{9} \sum_{x}\left[k_{14} \cdot C_{\mathrm{n}-\mathrm{P}}-k_{13} \cdot C_{\mathrm{N}_{6}} \cdot C_{\mathrm{H}_{2}}\right] \\
& Q_{10}=\Delta \mathrm{H}_{10} \sum_{x}\left[k_{18} \cdot C_{\mathrm{N}_{5}}-k_{17} \cdot C_{\mathrm{UICP}}\right] \\
& Q_{11}=\Delta \mathrm{H}_{11} \sum_{x}\left[k_{10} \cdot C_{\mathrm{Ar}}-k_{19} \cdot C_{\mathrm{UICP}}\right] \\
& Q_{12}=-\Delta \mathrm{H}_{12} \sum_{x} k_{21} \cdot C_{\mathrm{UICP}} \\
& Q_{13}=-\Delta \mathrm{H}_{13} \sum_{x} k_{22} \cdot C_{\mathrm{Ar}} \cdot
\end{aligned}
$$

Thus, the mathematical model of semi-regenerative catalytic reforming of naphtha is presented by a system of equations of material and heat balances:

$$
\left\{\begin{array}{l}
G_{c} \frac{\partial C_{i}}{\partial Z}+G_{c} \frac{\partial C_{i}}{\partial V}=\sum_{j=1}^{m} a_{j} \cdot r_{j} \\
G_{c} \frac{\partial T}{\partial V}+G_{c} \frac{\partial T}{\partial Z}=\frac{1}{\rho \cdot C_{p}^{\text {mix }}} \sum_{j=1}^{m} a_{j} \cdot r_{j} \cdot\left(\frac{R T}{P}\right) \cdot \Delta H_{j}
\end{array} .\right.
$$


The boundary conditions are:

$$
\begin{array}{cc}
z=0, & C_{i}=C_{i 0}, \quad T=T_{\mathrm{en}} \\
V=0, & T=T_{\mathrm{en}},
\end{array}
$$

$G_{c}$ is a feedstock flow rate, $\mathrm{m}^{3} / \mathrm{h} ; C_{i}$ is a concentration of $i$ th component, $\mathrm{mol} / \mathrm{m}^{3} ; Z$ is a volume of feedstock processed from the moment when the fresh catalyst (new catalyst, no regenerations were done) was loaded, $\mathrm{m}^{3} ; V$ is a catalyst volume in the reactors, $\mathrm{m}^{3} ; a_{j}$ is a catalyst's activity; $r_{j}$ is a reaction's rate, $\mathrm{mol} / \mathrm{m}^{3} \mathrm{~h} ; i$ is a component number in a mixture; $j$ is a reaction number due to the accepted formalized scheme; $T$ is a temperature, $\mathrm{K} ; \rho$ is a density, $\mathrm{mol} / \mathrm{m}^{3}$; $C_{p}^{\text {mix }}$ is a heat capacity of the mixture, $\mathrm{kJ} / \mathrm{mol} \mathrm{K} ; k_{j}$ is the $j$ th reaction constant, $\mathrm{L} / \mathrm{mol} \mathrm{h} ; \Delta \mathrm{H}$ is a $j$ th reaction heat, $\mathrm{kJ} / \mathrm{mol} ; R$ is the gas constant, $8314 \mathrm{MPa} \mathrm{L} / \mathrm{mol} \mathrm{K} ; P$ is a pressure, MPa:

$$
Z=G \cdot t
$$

where $Z$ is a volume of feedstock processed from the moment when the fresh catalyst (new catalyst, no regenerations were done) was loaded, $\mathrm{m}^{3} ; G$ is a feedstock flow rate, $\mathrm{m}^{3} / \mathrm{h} ; t$ is a space time, $\mathrm{h}$,

$G \frac{\mathrm{d} C_{\mathrm{Ar}}}{\mathrm{d} V}=r_{2}+r_{19}-r_{1}-r_{20}-r_{22}$

$G \frac{\mathrm{d} C_{\mathrm{N}_{6}}}{\mathrm{~d} V}=r_{1}+r_{4}+r_{9}+r_{14}-r_{2}-r_{3}-r_{10}-r_{13}$

$G \frac{\mathrm{d} C_{\text {iso }-P}}{\mathrm{~d} V}=r_{3}+r_{11}+r_{15}-r_{5}-r_{12}-r_{4}$

$G \frac{\mathrm{d} C_{\mathrm{Ar}^{\prime}}}{\mathrm{d} V}=r_{22}+r_{2}-r_{1}+r_{19}-r_{20}$

$G \frac{\mathrm{d} C_{n-P}}{\mathrm{~d} V}=r_{11}+r_{7}+r_{13}-r_{6}-r_{8}-r_{12}-r_{16}$

$G \frac{\mathrm{d} C_{\mathrm{N}_{5}}}{\mathrm{~d} V}=r_{10}-r_{9}+r_{8}-r_{7}+r_{17}-r_{18}+r_{16}-r_{15}$

$G \frac{\mathrm{d} C_{\mathrm{UICP}}}{\mathrm{d} V}=r_{19}-r_{20}+r_{18}-r_{17}-r_{21}$

$G \frac{\mathrm{d} C_{\text {coke }}}{\mathrm{d} V}=r_{21}+r_{19}-r_{20}+r_{18}-r_{17}$

$G \frac{\mathrm{d} C_{G}}{\mathrm{~d} V}=r_{5}+r_{6}+r_{3}-r_{4}+r_{7}-r_{8}+r_{15}-r_{16}+r_{13}-r_{14}$.

The computer program based on this mathematical model was developed. The model enables to consider physical and chemical laws of hydrocarbons conversion on the catalyst surface and changes in the composition of the feedstock. With this model, such parameters as the current and optimal activities are calculated. The current activity is determined by the current modes of the operation:

$$
a_{\text {cur }}=W_{0}-W_{k}(1-\alpha),
$$

where $a_{j}-$ a relative activity of a catalyst in each reaction (7); $W_{0}-$ a chemical reaction rate, $\mathrm{mol} / \mathrm{sm}^{3} \mathrm{~s}$, with and without a catalyst; $\alpha$ - a part of the volume occupied by the catalyst and inaccessible for the reacting mixture [7].
The optimal activity $\left(a_{\text {opt }}\right)$ is defined by the optimal process operation which corresponds to the desired rate ratio of the target and adverse reactions, and also save the equilibrium of formation and hydrogenation of the coke structures, which is described by the process parameters namely temperature, pressure, feedstock composition. The optimal activity provides maximum process selectivity.

As a common indicator of the catalyst potential, a special criterion of effectiveness was proposed. This criterion corresponds to the deviation of the current activity from the optimal one [17-19]:

$$
\Delta=\frac{\sum_{i=1}^{n}\left[a_{\mathrm{cur}}^{i}-a_{\mathrm{opt}}^{i}\right]}{\Delta_{\max }},
$$

where $\Delta-$ a criterion of effectiveness; $a_{\text {cur }}^{i}$ - a current activity; $a_{\mathrm{opt}}^{i}-$ an optimal activity; $\Delta_{\max }-$ maximum deviation of the current activity from the optimal one.

With this characteristic of the catalyst potential, it is possible to determine the degree of effectiveness, the catalyst is used on a reforming unit. This criterion also determines the coke formation dynamics and selectivity with different types of the catalyst activity and the deviation between them corresponds to this criterion. All these calculations were made with the mathematical model to increase the yield and decrease the coke formation dynamics during the catalyst life operation, that leads to process optimization and its profitability improving.

\section{Results and discussion}

Polymetallic catalysts with high stability and selectivity play the key role in catalytic reforming of naphtha and improvement of its characteristics is a vital issue for the process optimization. In this paper a comparison of two different Pt-Re catalysts was done with the help of the mathematical model. The catalysts were loaded on the same catalytic reforming unit. The specifications of the reactors, operating conditions, feedstock, product and catalyst properties are presented in Tables 1-3.

The experimental data including the chromatographic analyzes results of feedstock and product compositions, the technological modes of the production unit operation were obtained from two different industrial SSR reforming units of the Russian refinery and were used as the initial data.

\subsection{Verification of the mathematical model}

To verify the model developed, a comparison between experimental and calculated results have been made for each SRR unit. Specifications of technological operation, naphtha feed, product and catalysts are provided in Tables 1-3. Experimental data are obtained from oil-refining plants, calculated results are performed with the mathematical model using.

Comparing the values presented in Tables 4 and 5, we can see, that data calculated on model agree very well with 
Table 1. Specifications of reactors and operating conditions of SRR units.

\begin{tabular}{lcc}
\hline Parameter & \multicolumn{2}{c}{ Numerical value } \\
\cline { 2 - 3 } & Unit 1 & Unit 2 \\
\hline Reactors inlet temperature, ${ }^{\circ} \mathrm{C}$ & 490 & 480 \\
Pressure, $\mathrm{MPa}$ & 2.0 & 1.7 \\
${\text { Mass flow rate, } \mathrm{h}^{-1}}^{\text {Diameter, length and volume of, } \mathrm{m} ; \mathrm{m} ; \mathrm{m}^{3}:}$ & $1.0-1.8$ & 1.4 \\
Reactor 1 & & $1.86 ; 6.49 ; 12.1$ \\
Reactor 2 & $2.40 ; 10.6 ; 13.0$ & $2.00 ; 7.00 ; 16.4$ \\
Reactor 3 & $3.20 ; 11.9 ; 38.0$ & $3.2 ; 10.7 ; 60.0$ \\
Reactor 4 & $4.00 ; 13.9 ; 76.0$ & $4.0 ; 13.05 ; 118$ \\
\hline
\end{tabular}

Table 2. Specifications of naphtha feed and reformate.

\begin{tabular}{|c|c|c|}
\hline Parameter & Naphtha feed & Reformate \\
\hline \multicolumn{3}{|c|}{ Unit 1} \\
\hline Density at $20{ }^{\circ} \mathrm{C}, \mathrm{kg} / \mathrm{m}^{3}$ & 755 & $800-830$ \\
\hline \multicolumn{3}{|l|}{ Distillation fraction, ${ }^{\circ} \mathrm{C}$ : } \\
\hline IBP & 85 & 85 \\
\hline FBP & 180 & 218 \\
\hline \multicolumn{3}{|l|}{ Group composition, $\%$ mas.: } \\
\hline Aromatic hydrocarbons & 15.0 & $57.0-65.0$ \\
\hline Naphtenes & $30.0-45.0$ & $2.80-4.00$ \\
\hline Alkanes & $45.0-60.0$ & $25.0-35.0$ \\
\hline \multicolumn{3}{|c|}{ Unit 2} \\
\hline Density at $20{ }^{\circ} \mathrm{C}, \mathrm{kg} / \mathrm{m}^{3}$ & $720-750$ & $750-810$ \\
\hline \multicolumn{3}{|l|}{ Distillation fraction, ${ }^{\circ} \mathrm{C}$ : } \\
\hline IBP & 80 & 70 \\
\hline FBP & 180 & 205 \\
\hline \multicolumn{3}{|l|}{ Group composition, $\%$ mas.: } \\
\hline Aromatic hydrocarbons & $8.00-14.5$ & $55.0-67.0$ \\
\hline Naphtenes & $34.5-40.0$ & $2.10-3.80$ \\
\hline Alkanes & $49.0-55.0$ & $30.0-41.0$ \\
\hline
\end{tabular}

Table 3. Specifications of catalyst properties.

\begin{tabular}{lccccc}
\hline Properties of a catalyst & R-98 & RB 33U Grade Sh & RB 44U Grade Sh & PR-9 & PR-81* \\
\hline Pt, wt.\% & 0.25 & 0.30 & 0.25 & 0.25 & 0.25 \\
Re, wt.\% & 0.25 & 0.30 & 0.40 & 0.25 & 0.30 \\
Packed density, $\mathrm{kg} / \mathrm{m}^{3}$ & 720 & $700-800$ & $700-800$ & 720 & 750 \\
Promoted by chlorine & No & Yes & Yes & Yes & Yes \\
\hline
\end{tabular}

* The development of Institute of Hydrocarbons Processing of the Siberian Branch of the RAS.

the experimental data from the industrial units (the calculation error should not exceed an error of chromatographic analysis).

In our case the average calculation error is less than 1 wt.\%.

\subsection{Evaluation of catalyst work efficiency in the presence of catalyst coking}

The efficiency of the catalysts was evaluated. In these calculations the SRR unit 1 were used (Tabs. 1-3). The changes 
Table 4. Comparison between experimental and calculated data of catalytic reforming process.

\begin{tabular}{lcccc}
\hline Research octane number & & \multicolumn{2}{c}{ Product yield, wt.\% } \\
\cline { 1 - 2 } Experiment & Calculation & & Experiment & Calculation \\
\hline & & Unit 1 & & 84.4 \\
94.1 & 95.5 & & 83.0 & 83.0 \\
94.3 & 95.3 & & 83.1 & 84.5 \\
91.7 & 93.0 & & & 87.7 \\
95.5 & 94.9 & Unit 2 & 88.0 & 88.2 \\
96.7 & 94.9 & & 87.6 & 87.3 \\
96.0 & 94.7 & & 88.1 & \\
\hline
\end{tabular}

Table 5. Experimental and calculated data of naphtha hydrocarbon composition.

\begin{tabular}{|c|c|c|c|c|c|c|c|c|c|}
\hline \multicolumn{2}{|c|}{$\begin{array}{l}\text { n-Alkanes, } \\
\text { wt. } \%\end{array}$} & \multicolumn{2}{|c|}{$\begin{array}{l}\text { i-Alkanes, } \\
\text { wt.\% }\end{array}$} & \multicolumn{2}{|c|}{$\begin{array}{l}\text { Naphthenes- } 5 \text {, } \\
\text { wt. } \%\end{array}$} & \multicolumn{2}{|c|}{$\begin{array}{l}\text { Naphthenes- } 6 \text {, } \\
\text { wt. } \%\end{array}$} & \multicolumn{2}{|c|}{$\begin{array}{c}\text { Aromatic } \\
\text { hydrocarbons, wt.\% }\end{array}$} \\
\hline Calc. & Exp. & Calc. & Exp. & Calc. & Exp. & Calc. & Exp. & Calc. & Exp. \\
\hline \multicolumn{10}{|c|}{ Unit 1} \\
\hline 7.11 & 8.05 & 24.3 & 22.3 & 2.63 & 2.36 & 0.80 & 0.82 & 65.2 & 65.2 \\
\hline 8.08 & 8.13 & 24.1 & 22.9 & 2.42 & 2.40 & 0.80 & 1.00 & 64.6 & 64.7 \\
\hline 8.77 & 9.12 & 26.2 & 24.7 & 2.61 & 2.71 & 0.92 & 1.09 & 61.5 & 61.5 \\
\hline \multicolumn{10}{|c|}{ Unit 2} \\
\hline 9.62 & 8.90 & 22.2 & 22.1 & 2.39 & 2.01 & 0.55 & 0.92 & 65.2 & 65.2 \\
\hline 8.42 & 8.59 & 21.2 & 19.8 & 2.42 & 2.37 & 0.41 & 0.87 & 67.5 & 67.6 \\
\hline 8.99 & 9.12 & 21.7 & 21.2 & 2.99 & 2.13 & 0.50 & 0.86 & 65.8 & 65.8 \\
\hline
\end{tabular}

Table 6. Evaluation of R-98 catalyst potential in the last operating cycle.

\begin{tabular}{|c|c|c|c|c|c|}
\hline \multirow{2}{*}{$\begin{array}{l}\text { Volume of processed feedstock, } \\
\text { thousands of tons }\end{array}$} & \multicolumn{2}{|c|}{ Activity } & \multicolumn{2}{|c|}{ Yield, wt.\% } & \multirow{2}{*}{$\begin{array}{l}\text { Criterion of } \\
\text { efficiency, } \Delta\end{array}$} \\
\hline & $\overline{\text { Current }}$ & Optimal & $\overline{\text { Current }}$ & $\overline{\text { Optimal }}$ & \\
\hline 41.0 & 0.76 & 0.86 & 81.6 & 84.0 & 0.71 \\
\hline 81.3 & 0.78 & 0.84 & 81.7 & 84.5 & 0.43 \\
\hline 124 & 0.80 & 0.81 & 81.4 & 85.1 & 0.29 \\
\hline 294 & 0.81 & 0.82 & 81.7 & 83.3 & 0.07 \\
\hline 382 & 0.81 & 0.83 & 82.0 & 85.0 & 0.14 \\
\hline 471 & 0.79 & 0.85 & 82.1 & 85.1 & 0.43 \\
\hline 608 & 0.81 & 0.90 & 82.5 & 84.8 & 0.64 \\
\hline 632 & 0.82 & 0.89 & 81.9 & 84.9 & 0.50 \\
\hline
\end{tabular}

in the current activity of R-98 during its sixth operating cycle are shown in Table 6.

At the beginning of the last operation period, the catalyst activity was 0.76 , and reached its maximum at the end - 0.82. This deviation influences the yield (Tab. 4).

Making a comparison between all cycles (Fig. 2), it may be noted, that the average activity does not exceed 0.86 .
The fourth cycle has the lowest activity due to the changes in the feedstock composition and the aging process of the catalyst.

It is shown in Figure 3, that a high selectivity $(85-86$ wt.\%) is observed in the first, third and fourth cycles. In the second cycle, the yield sharply reduced (81 wt.\%) due to the poor regeneration. The fourth cycle shows the highest 


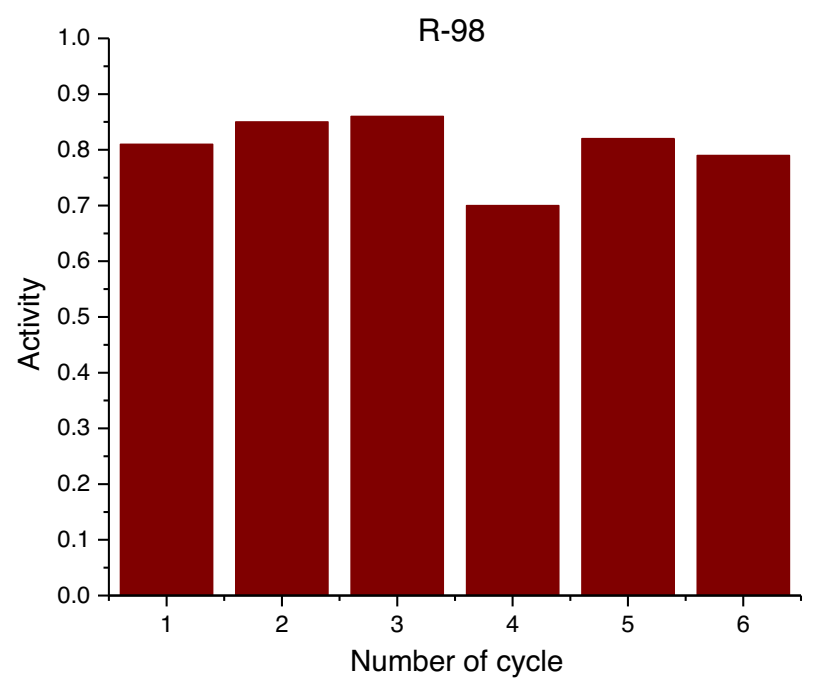

Fig. 2. Comparison of R-98 catalyst current activity (model calculation results).

yield (86 wt.\%), but in the fifth and sixth cycles the yield is in the range of $81-84$ wt.\%. This fact can be explained by the process of catalyst aging.

The yield and octane number of the product are interrelated with each other. Figure 3 shows that the lowest selectivity cycles correspond to the highest quality products. The average value of research octane number is in the range of $93-97$, while the desirable RON is 92 . Maintaining the optimal mode of the process, it can be possible to achieve a higher yield of desirable quality. In general, the R-98 catalyst shows very good results throughout the entire period of its operation, it allows obtaining a high-quality product.

The R-98 catalyst was used successfully during 6 cycles and then was replaced for the composition of the two catalysts RB 33U/RB 44U Grade Sh. With the mathematical model, the evaluation of RB 33U/RB 44U Grade Sh efficiency was carried out.

Figure 4 and Table 7 show that the reforming unit in both of the cycles was close to the optimal mode.

In the first cycle the catalyst activity varies in the range from 0.75 to 1.20 , in the second - from 0.95 to 1.30 . The difference between the current and optimal modes is not significant. It can be concluded that the catalyst is used quite effectively. The two cycles were compared (Fig. 5), it may be observed that the current activity in the second cycle exceeds by 0.20 the activity in the first cycle. This fact can be associated with the changes in the hydrocarbon composition of the feedstock and the technological mode, or the effective regeneration of the catalyst.

Figure 6 shows, that the yield with the current activity exceeds the yield with the optimal activity. The yield achieved 91 wt. $\%$, the deviation of the current mode from the optimal one in the first cycle is $0.3 \mathrm{wt} . \%$, in the second -1.0 wt. $\%$.

However, analyses of the quality of the product (Fig. 6) speaks for the fact that in both of the cycles, the octane number varies in the range from 88.5 to 92.0 with desirable $\mathrm{RON}=92$. Maintaining the optimal mode of the process, the yield of the desirable quality will not greatly differ from the current mode.

Using the proposed computer modeling system based on the mathematical model, it is possible to monitor the industrial catalytic reforming unit and evaluate the catalyst potential numerically equal to the deviation of the current activity from the optimal one. The yield is dependent on the activity and changes in its value.

The regulation of the catalyst activity allows the efficiency of catalytic reforming process to be rised by an increase in the yield and duration of the operating cycle of the catalyst. Application of the computer modeling system based on the mathematical model enables to consider changes in the operating conditions, feedstock composition and coke formation.

The coke is progressively accumulated and distributed on the surface of the catalyst during its operation. Coke formation process is the reversible reason of catalyst deactivation and the coke depositions can be removed from the surface [1, 29].

The model considers coke formation process as one of the formalized scheme reactions and its concentration can be calculated according to equation (4). The mechanism of coke formation can be represented by the scheme of the sequential reactions: hydrocarbons $\rightarrow$ resins $\rightarrow$ asphaltenes $\rightarrow$ coke, where resins and asphaltenes are Unsaturated Immediate Compacting Products (UICP). The formation and hydrogenation of unsaturated intermediate products of compaction are possible. Therefore, under certain conditions coke formation does not occur, because asphaltenes (the precursors of coke) can hydrogenate to hydrocarbons or can be in equilibrium with gas-phase reaction medium.

Thus, by controlling of the feedstock temperature in a reactor, it could be possible to provide the process operation mode with the equilibrium of formation and hydrogenation of the coke structures. However, it is difficult to apply in practice, because it is required to obtain the final highoctane product, so there is an objective need for the deviations from the thermodynamic equilibrium. As a result, accumulation of unsaturated intermediate products of compaction occurs.

With the mathematical model the coke concentration is calculated. The coke accumulation rate at the optimal operating conditions differs from the current one (Tab. 8).

The mathematical model application allows analyzing the rate of coke accumulation in the current period and helps to choose the optimal technological conditions for the process. The regulation of the rate of coke accumulation using the developed mathematical model allows extending the operating cycle, while maintaining the high selectivity.

\subsection{Optimization of SRR catalytic reforming process by pressure reducing}

The operating conditions strongly affect the process characteristics such as the yield, octane number and coke accumulation rate. Such reactions as naphthenic dehydrogenation and paraffin dehydrocyclization are favored at low pressure, 

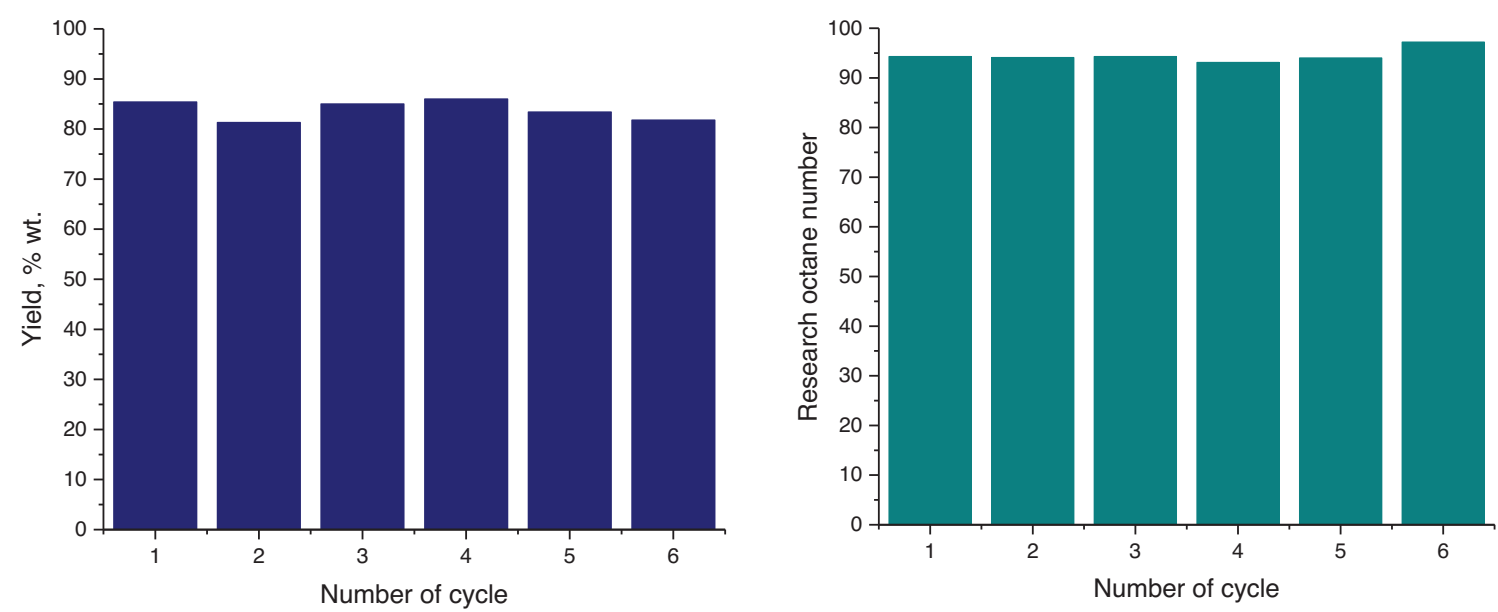

Fig. 3. Comparison of reformate yield and octane number (model calculation results).
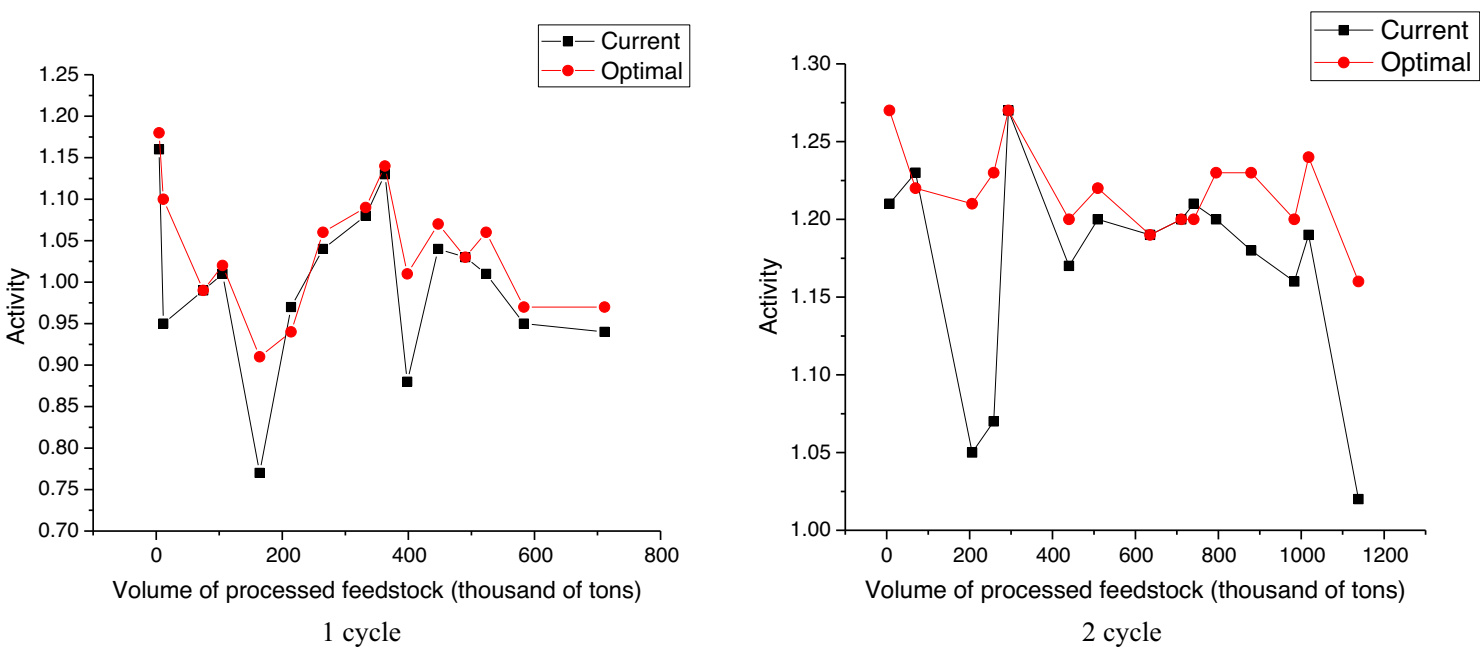

Fig. 4. Comparison between current and optimal activity of catalyst RB 33U/RB 44U Grade Sh (model calculation results).

Table 7. Evaluation of RB 33U/RB 44U Grade Sh catalyst potential in the second operating cycle (model calculation results).

\begin{tabular}{|c|c|c|c|c|c|}
\hline \multirow{2}{*}{$\begin{array}{l}\text { Volume of processed feedstock, } \\
\text { thousands of tons }\end{array}$} & \multicolumn{2}{|c|}{ Activity } & \multicolumn{2}{|c|}{ Yield, wt.\% } & \multirow{2}{*}{$\begin{array}{l}\text { Criterion of } \\
\text { efficiency, } \Delta\end{array}$} \\
\hline & Current & Optimal & Current & Optimal & \\
\hline 206 & 1.05 & 1.21 & 91.1 & 90.2 & 1.00 \\
\hline 440 & 1.17 & 1.20 & 89.7 & 89.4 & 0.19 \\
\hline 509 & 1.20 & 1.22 & 89.9 & 89.8 & 0.13 \\
\hline 795 & 1.20 & 1.23 & 90.0 & 89.8 & 0.19 \\
\hline 879 & 1.18 & 1.23 & 90.3 & 89.9 & 0.31 \\
\hline 983 & 1.16 & 1.20 & 90.2 & 89.9 & 0.25 \\
\hline 1018 & 1.19 & 1.24 & 90.6 & 90.3 & 0.31 \\
\hline 1138 & 1.02 & 1.16 & 90.5 & 89.7 & 0.88 \\
\hline
\end{tabular}




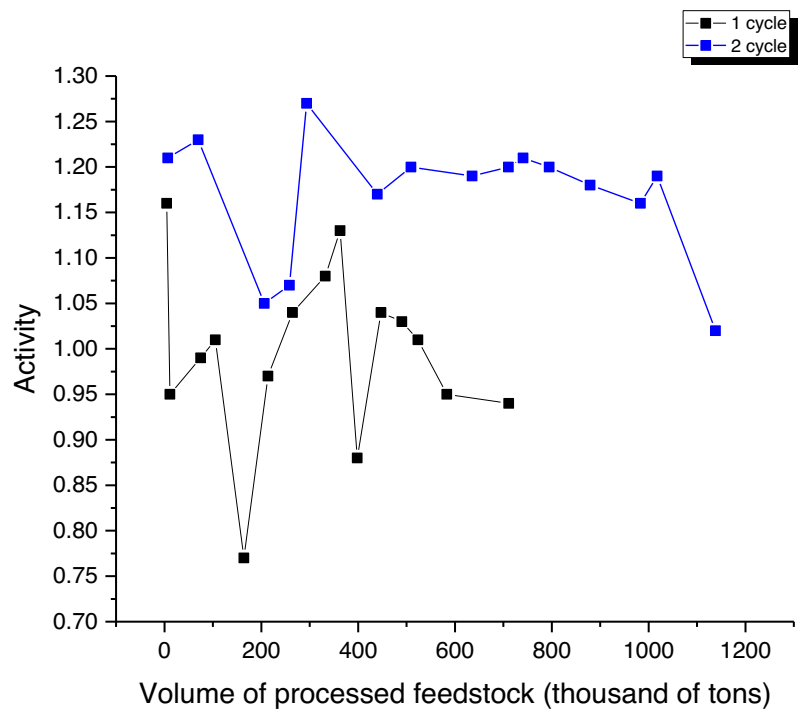

Fig. 5. Comparison of $\mathrm{RB} 33 \mathrm{U} / \mathrm{RB} 44 \mathrm{U}$ Grade Sh catalyst activity in two cycles (model calculation results).

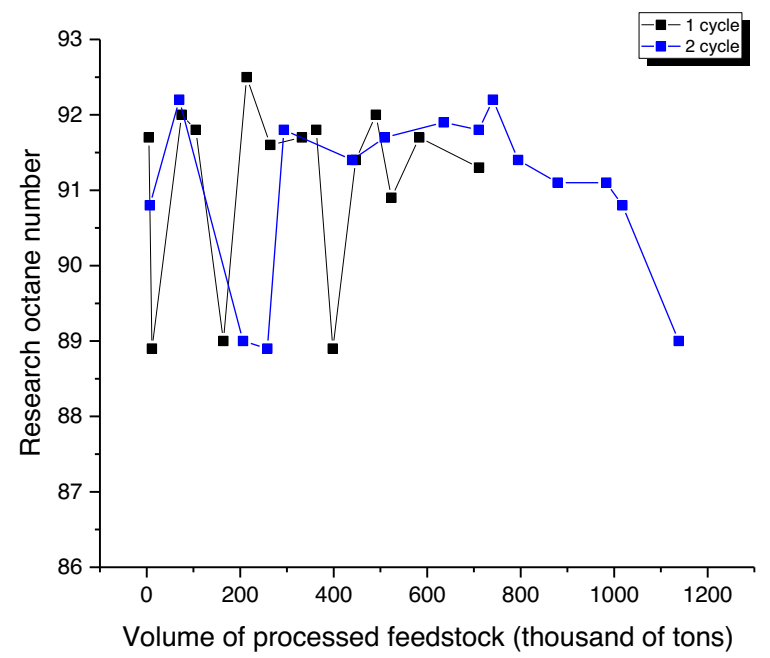

Fig. 6. Change in octane number (model calculation results).

while hydrocracking and hydrogenolysis side reactions are inhibited at the same conditions. This fact can be successfully used in the process optimization. The effect of the total pressure on the product yield and catalyst coking was analyzed with the mathematical model. These calculations were performed with the data from SRR unit 2 (Tabs. 1-3).

At low pressure, the rate of paraffin aromatization increases, while the rate of hydrocracking decreases. This leads to the hydrogen yield and aromatics gradual increase by $0.2 \%$ and $1-2 \%$ respectively. The hydrogen yield growth results in the product yield rise. Therefore, the total selectivity of the process increases (Fig. 7).

Analyzing influence of feedstock, we can see that its hydrocarbon composition (Tab. 9) in combination with
Table 8. Comparison of coke formation on the surface of R-98 catalyst between current and optimal activity (model calculation results).

\begin{tabular}{lccc}
\hline \multirow{2}{*}{$\begin{array}{l}\text { A volume of } \\
\text { processed feedstock, } \\
\text { thousands of tons }\end{array}$} & \multicolumn{3}{c}{ R-98 } \\
\cline { 2 - 3 } & Coke, wt.\% & Deviation \\
\cline { 2 - 3 } & Current & Optimal & \\
\hline 21.8 & 0.15 & 0.15 & 0.00 \\
41.0 & 0.34 & 0.31 & 0.03 \\
60.8 & 0.52 & 0.45 & 0.07 \\
81.3 & 0.74 & 0.60 & 0.14 \\
103 & 1.01 & 0.77 & 0.24 \\
124 & 1.27 & 0.94 & 0.33 \\
145 & 1.56 & 1.08 & 0.48 \\
166 & 1.84 & 1.23 & 0.61 \\
230 & 2.68 & 1.59 & 1.09 \\
294 & 3.64 & 2.14 & 1.50 \\
316 & 3.96 & 2.26 & 1.70 \\
338 & 4.23 & 2.42 & 1.81 \\
382 & 4.79 & 2.72 & 2.07 \\
404 & 5.06 & 2.88 & 2.18 \\
426 & 5.38 & 3.03 & 2.35 \\
\hline
\end{tabular}

pressure reduction has a strong effect on the process (Tabs. 10 and 11).

Despite this positive effect, low pressure contributes to the catalyst deactivation due to coking reactions rate increase (Fig. 8).

Thus, by reduction of pressure, it is possible to increase the yield and octane number, hydrogen and aromatic hydrocarbons due to the equilibrium shift of the reactions of dehydrogenation and dehydrocyclization. At the same time, pressure reduction accelerates coke formation process that leads to rapid catalyst deactivation and shortening of its operation cycle.

In this connection, it is necessary to determine the optimal process conditions under which the maximum yield of the given quality is achieved, but coke formation does not limit the rate of the target reactions. The quantity of the target product, expressed in octanes per tons, is taken as an optimal criterion:

$$
\omega=\frac{w \cdot \mathrm{RON}}{100},
$$

where $\omega-$ a yield in octanes per tons; $w$ - a yield, wt.\%; RON - a research octane number.

The limiting condition that does not allow reducing the pressure to a minimum is the coke formation rate increasing with a pressure decrease. The solution to this optimization problem will be to find the optimal solution (optimum), at which the maximum yield of a product of the given quality will be achieved, while not significantly exceeding the coke formation rate, leading to rapid deactivation of the Pt catalyst (Fig. 9). 

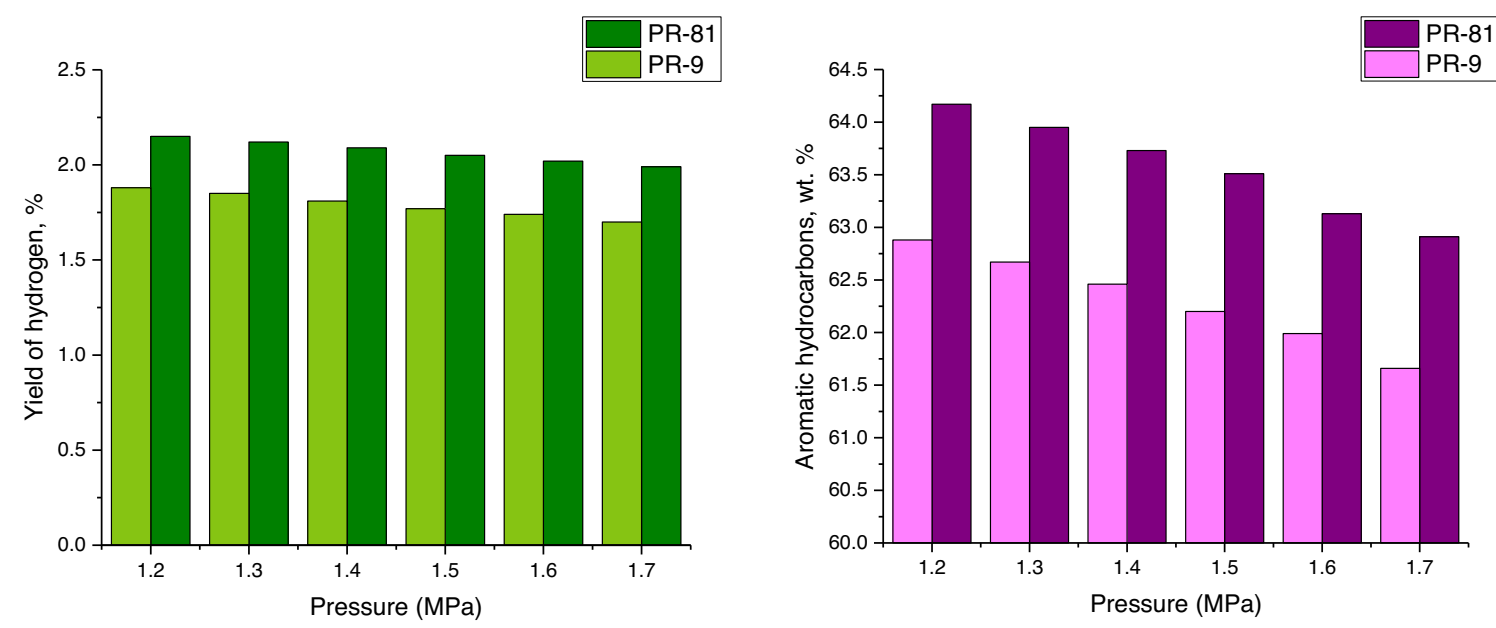

Fig. 7. Comparison of pressure effect on the hydrogen and aromatics yield between two catalysts (simulation results).

Table 9. Operating conditions and composition of feedstock.

\begin{tabular}{|c|c|c|c|}
\hline Parameter & Feedstock no. 1 & Feedstock no. 2 & Feedstock no. 3 \\
\hline A volume of processed feedstock, tons & & 341629 & \\
\hline Hydrogen, $\%$ & & 86.7 & \\
\hline Temperature, ${ }^{\circ} \mathrm{C}$ & & 482 & \\
\hline Mass flow rate, $\mathrm{m}^{3} / \mathrm{h}$ & & 68.0 & \\
\hline n-Alkanes, wt.\% & 186 & 17.8 & 18.3 \\
\hline i-Alkanes, wt.\% & 27.4 & 26.2 & 26.6 \\
\hline Naphthenes, wt.\% & 35.1 & 35.8 & 35.2 \\
\hline Aromatic hydrocarbons, wt.\% & 17.4 & 18.3 & 17.2 \\
\hline
\end{tabular}

Table 10. The change in SRR process parameters with hydrocarbon composition of feedstock and pressure variation for PR-9 (simulation results).

\begin{tabular}{|c|c|c|c|c|c|c|c|c|c|}
\hline \multirow{2}{*}{$\frac{\text { Parameter }}{\text { Pressure, } \mathrm{MPa}}$} & \multicolumn{3}{|c|}{ Feedstock no. 1} & \multicolumn{3}{|c|}{ Feedstock no. 2} & \multicolumn{3}{|c|}{ Feedstock no. 3} \\
\hline & 1.6 & 1.4 & 1.2 & 1.6 & 1.4 & 1.2 & 1.6 & 1.4 & 1.2 \\
\hline Yield of hydrogen, $\%$ & 1.79 & 1.83 & 1.91 & 1.78 & 1.85 & 1.93 & 1.74 & 1.81 & 1.89 \\
\hline Aromatic hydrocarbon, wt.\% & 62.5 & 63.0 & 63.5 & 63.3 & 63.8 & 64.3 & 61.6 & 62.2 & 62.6 \\
\hline Research octane number & 91.8 & 92.1 & 92.4 & 94.0 & 94.3 & 94.5 & 93.5 & 93.8 & 94.0 \\
\hline Yield, wt.\% & 86.3 & 86.8 & 87.3 & 86.7 & 87.2 & 87.6 & 86.5 & 87.0 & 87.5 \\
\hline
\end{tabular}

Table 11. Change in SRR process parameters with hydrocarbon composition of feedstock and pressure variation for PR-81 (simulation results).

\begin{tabular}{|c|c|c|c|c|c|c|c|c|c|}
\hline \multirow{2}{*}{$\frac{\text { Parameter }}{\text { Pressure, MPa }}$} & \multicolumn{3}{|c|}{ Feedstock no. 1} & \multicolumn{3}{|c|}{ Feedstock no. 2} & \multicolumn{3}{|c|}{ Feedstock no. 3} \\
\hline & 1.6 & 1.4 & 1.2 & 1.6 & 1.4 & 1.2 & 1.6 & 1.4 & 1.2 \\
\hline Yield of hydrogen, $\%$ & 1.91 & 1.94 & 2.02 & 1.84 & 2.00 & 2.09 & 1.73 & 2.07 & 2.15 \\
\hline Aromatic hydrocarbon, wt.\% & 60.7 & 62.8 & 63.1 & 61.3 & 63.0 & 63.7 & 61.8 & 63.1 & 64.2 \\
\hline Research octane number & 92.3 & 92.7 & 92.9 & 94.1 & 94.3 & 94.5 & 93.2 & 93.6 & 93.8 \\
\hline Yield, \%mas. & 89.2 & 89.8 & 89.9 & 89.5 & 90.4 & 90.2 & 89.9 & 91.0 & 90.5 \\
\hline
\end{tabular}




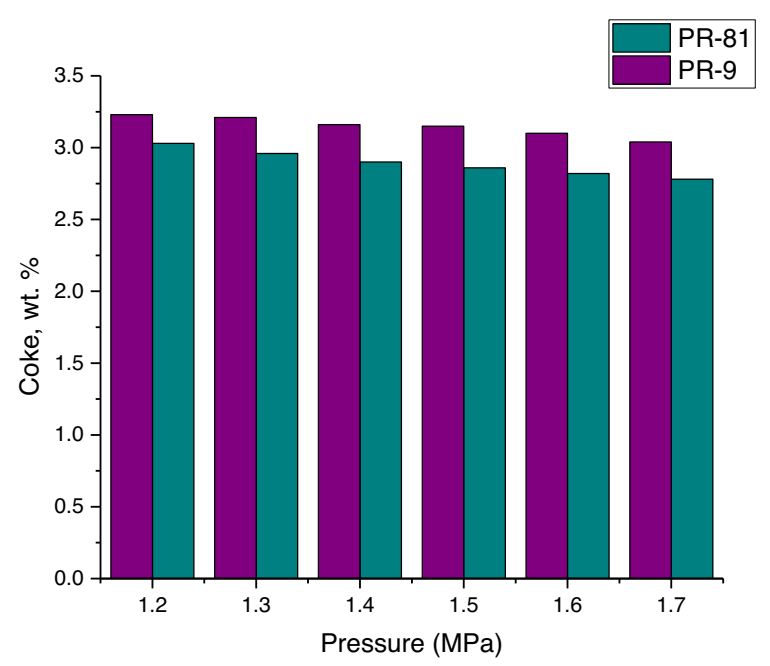

Fig. 8. Coke accumulation on the catalysts with pressure (simulation results).

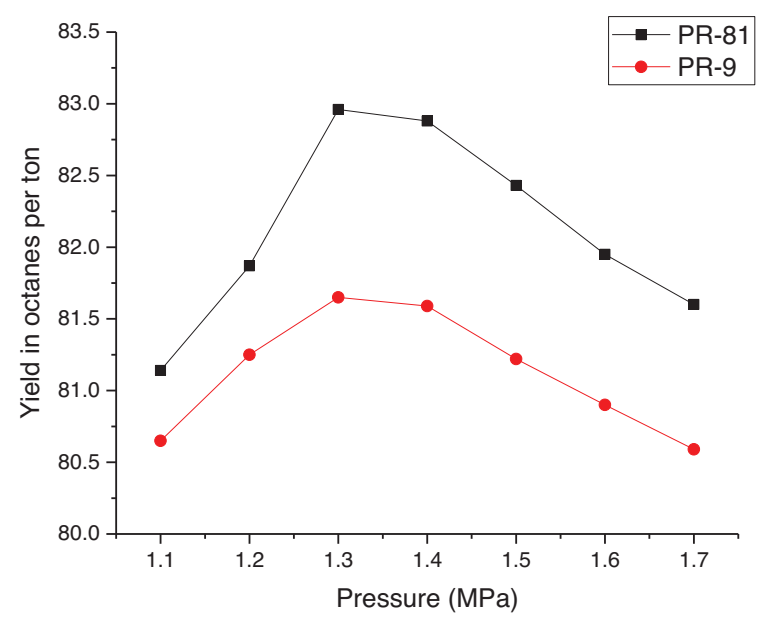

Fig. 9. Change in yield with pressure (simulation results).

Therefore, it is not recommended to maintain pressure below $1.4-1.2 \mathrm{MPa}$ in order to prevent rapid catalyst deactivation.

\section{Conclusion}

In this paper the optimization approach for SRR catalytic reforming process is introduced. The approach is based on mathematical model application. The model takes into account the catalyst activity, operation instability and changes in hydrocarbon composition of the feedstock. The model enables to monitor the industrial process and find the optimal mode of the operation, which is determined by the equilibrium conditions for the reactions of coke formation and hydrogenation of the intermediate compaction products.
With the mathematical model, it is possible to improve technical values of the industrial process, such as the yield and octane number of the product increase. Besides, mathematical modeling allows evaluating the efficiency of catalyst and can help to make a decision about its replacement for a new one. The studies have shown that the yield of a product of the desirable quality increases by $4 \mathrm{wt} . \%$ in case of it replacement.

It was found, that a decrease in the pressure range from 1.5 to $1.2 \mathrm{MPa}$ at the temperature $478-481{ }^{\circ} \mathrm{C}$ and feedstock space velocity is $1.4-1 \mathrm{~h}$ induces an increase in the yield of 1-2 wt.\% due to an increase in the aromatization reaction rate and decrease in the hydrocracking reaction rate depending on the feedstock composition and catalyst type, but at the same time do not influences the isomerization reactions rate.

It is shown that the decrease in pressure is limited by the requirements for the catalyst stability due to the increase in the coke formation rate. It was found that when the temperature at the reactor inlet is $478{ }^{\circ} \mathrm{C}$, the feedstock flow rate is $64.3 \mathrm{~m}^{3} / \mathrm{h}$ and there is more naphthenic feedstock, the total amount of coke is evenly increased by 0.5-1.0 wt.\% depending on pressure and catalyst type.

It is proposed that the criterion of optimality is the yield expressed in octane per tons. It was calculated with the mathematical model that with the naphthenic feedstock, the pressure should vary in the range from 1.3 to $1.5 \mathrm{MPa}$.

Finally, the model considers the process of catalyst deactivation by coke. There is no possibility to prevent this process fully, but with the mathematical model application, it is possible to monitor and correct the technological regime. Catalytic reforming process optimization can be achieved with the technological conditions improvement and optimal regime provision. Both ways of the process optimization contribute to the product yield increase and coking reduction.

\section{References}

1 Rahimpour M.R., Jafari M., Iranshahi D. (2013) Progress in catalytic naphtha reforming process: A review, Appl. Energy 109, 79-93.

2 Sharikov Yu.V., Petrov P.A. (2007) Universal model for catalytic reforming, Chem. Petrol. Eng. 43, 580-584.

3 Froment G.F. (2001) Modeling of catalyst deactivation, Appl. Catal. A: Gen. 212, 117-128.

4 Aguayo A.T., Gayubo A.G., Atutxa A., Olazar M., Bilbao J. (2002) Catalyst deactivation by coke in the transformation of aqueous ethanol into hydrocarbons. Kinetic modeling and acidity deterioration of the catalyst, Ind. Eng. Chem. Res. 41, 4216-4224.

5 Ancheyta J., Villafuerte-Macias E. (2000) Kinetic modeling of naphtha catalytic reforming reactions, Energy Fuels 14, 1032-1037.

6 Stijepovic M.Z., Ostojic A., Milenkovic I., Linke P. (2009) Development of a kinetic model for catalytic reforming of naphtha and parameter estimation using industrial plant data, Energy Fuels 23, 979-983.

7 Rodríguez M.A., Ancheyta J. (2011) Detailed description of kinetic and reactor modeling for naphtha catalytic reforming, Fuel 90, 3492-3508. 
8 Taskar U., Riggs J.B. (1997) Modeling and optimization of a semiregenerative catalytic naphtha reformer, AIChE J. 3, 740-753.

9 Padmavathi G., Chaudhuri K.K. (1997) Modelling and simulation of commercial catalytic naphtha reformers, Can. J. Chem. Eng. 75, 930-938.

10 Kern C., Jess A. (2005) Regeneration of coked catalysts modelling and verification of coke burn-off in single particles and fixed bed reactors, Chem. Eng. Sci. 60, 4249-4264.

11 Gyngazova M.S., Kravtsov A.V., Ivanchina E.D., Korolenko M.V., Chekantsev N.V. (2011) Reactor modeling and simulation of moving-bed catalytic reforming process, Chem. Eng. J. 176-177, 134-143.

12 Belyi A.S. (2005) Reforming catalysts of the PR family: Scientific Foundations and Technological Advancement, Kinet. Catal. 46, 684-692.

13 Hou W., Su H., Hu Y., Chu J. (2006) Modeling, simulation and optimization of a whole industrial catalytic naphtha reforming process on Aspen Plus platform, Chin. J. Chem. Eng. 14, 584-591.

14 Lid T., Skogestad S. (2008) Data reconciliation and optimal operation of a catalytic naphtha reformer, J. Process Control. 18, 320-331.

15 Hongjun Z., Mingliang S., Huixin W., Zeji L., Jiang H. (2010) Modeling and simulation of moving bed reactor for catalytic naphtha reforming, Pet. Sci. Technol. 28, 667-676.

16 Syed A.A., Mohammed A.S., Mohammed A.A. (2006) Parametric study of catalytic reforming process, React. Kinet. Catal. Lett. 87, 199-206.

17 Yakupova I.V., Ivanchina E.D., Sharova E.S., Syskina A.A. (2014) Computer modelling system application for catalytic reforming unit work optimization, Procedia Chem. 10, 192-196.

18 Belinskaya N.S., Ivanchina E.D., Ivashkina E.N., Chuzlov V.A., Faleev S.A. (2015) Mathematical modeling of the process of catalytic hydrodewaxing of atmospheric gasoil considering the interconnection of the technological scheme devices, Procedia Eng. 113, 68-72.

19 Ivanchina E.D., Ivashkina E.N., Nazarova G.U. (2017) Mathematical modelling of catalytic cracking riser reactor, Chem. Eng. J. 329, 262-274.

20 Ostrovskii N.M. (2005) Problems in the study of catalyst deactivation kinetics, Kinet. Catal. 46, 693-704.

21 Shakor Z., Abdulrazak A.A., Sukkar K. (2020) A detailed reaction kinetic model of heavy Naphtha reforming, AJSE 45, 7361-7370.

22 Arani H., Shirvani M., Safdarian K., Dorostkar E. (2009) Lumping procedure for a kinetic model of catalytic naphtha reforming, Braz. J. Chem. Eng. 26, 723-732.

23 Shanying H.U., Zhu X. (2004) Molecular modeling and optimization for catalytic reforming, Chem. Eng. Commun. 191, 500-512.

24 Ren X.-H., Bertmer M., Stapf S., Demco D.E., Blumich B., Kern C., Jess A. (2002) Deactivation and regeneration of a naphtha reforming catalyst, Appl. Catal. A-Gen. 228, 39-52.

25 Ostrovskii N.M. (2006) General equation for linear mechanisms of catalyst deactivation, Chem. Eng. J. 120, 73-82.

26 Zagoruiko A.N., Belyi A.S., Smolikov M.D., Noskov A.S. (2014) Unsteady-state kinetic simulation of naphtha reforming and coke combustion processes in the fixed and moving catalyst beds, Catal. Today. 220-227, 168-177.

27 Yakupova I.V., Ivanchina E.D., Sharova E.S. (2014) Mathematical modelling method application for optimisation of catalytic reforming process, Procedia Chem. 10, 197-202.

28 Davis S.M., Laura F., Somorjai G.A. (1982) The reactivity and composition of strongly adsorbed carbonaceous deposits on platinum. Model of the working hydrocarbon conversion catalyst.J. Catal. 77, 2, 439.

29 Dehghani O., Gholipour M.R., Shokrollahi M.S., Yancheshmeh S., Seifzadeh Haghigh S., Ghaemi M., Rahimpour M.R., Shariati A. (2013) A new configuration for decoking process in series reactors, Chem. Eng. J. 215-216, 418-431. 